\title{
Air pollutants and primary allergy prevention
}

\author{
Joachim Heinrich
}

Received: 11 April 2018 / Accepted: 15 May 2018 / Published online: 10 October 2018

(C) The Author(s) 2018

\begin{abstract}
Background Air pollutants such as particulate matter $\left(\mathrm{PM}_{2.5}\right)$ and nitrogen dioxide $\left(\mathrm{NO}_{2}\right)$ in outdoor air have long been suspected of causing the development of asthma and allergic rhinitis. However, a variety of systematic reviews have reached different conclusions in the last 15 years on whether these air pollutants do in actual fact play a causal role in the onset of asthma, allergic rhinitis, and eczema.

Methods Based on published systematic reviews and the most recent publications, the current state of knowledge on epidemiological evidence is presented and the potential for primary prevention of these allergic diseases by reducing or avoiding exposure to these air pollutants evaluated.

Results Despite conducting an extensive literature search, analyzing the most recent results, and focusing on the birth cohort studies most relevant to the question in hand, epidemiological results do not adequately support the concept of a causal relationship between the two air pollutants in question, $\mathrm{PM}_{2.5}$ and $\mathrm{NO}_{2}$, and asthma. Epidemiological studies predominantly show no effect of these air pollutants on allergic sensitization and the onset of allergic rhinitis. The small number of studies that have investigated the link between air pollutants and eczema largely revealed there to be no link.

Conclusion If the evidence for the causal role of air pollutants in the onset of allergies is inconclusive, one must assume that it is probably not possible to achieve
\end{abstract}

\section{Prof. Dr. J. Heinrich $(\bowtie)$}

Institute and Outpatient Clinic for Occupational, Social, and Environmental Medicine, WHO Collaborating Centre for Occupational Health, City Center Campus, University Hospital Munich, Ziemssenstraße 1, 80336 Munich, Germany

joachim.heinrich@med.uni-muenchen.de primary prevention of allergies by improving air quality. However, there is sufficient evidence to show that air pollutants can trigger exacerbations of allergic diseases. This alone justifies ensuring that the existing threshold values for air pollutants are adhered to, in order to protect particularly allergy sufferers from health impairments.

Keywords Particulate matter - Nitrogen dioxide . Asthma · Allergic rhinitis · Allergic sensitization
Abbreviations
COPD Chronic obstructive pulmonary disease
GIS Geographic information systems
IgE Immunoglobulin E
LUR Land-use regression model (to determine the distribution of air pollutants)
NO Nitrogen monoxide
$\mathrm{NO}_{2} \quad$ Nitrogen dioxide
PM Particulate matter
$\mathrm{SO}_{2} \quad$ Sulfur dioxide
TRAP Traffic-related air pollution
Th2 Type 2T-helper cells
UFP Ultrafine particles
VOC Volatile organic compounds

\section{Introduction}

Ambient air always contains a mixture of numerous substances that have been shown to have adverse health effects. Extensive scientific evidence has demonstrated incontrovertibly that pollutants in ambient air can harm not only the lungs, but also the cardiovascular system. Particulate matter (PM) is considered the most important air pollutant for the healthy general population, followed by ozone, which affects the respiratory tract in particular. No distinction is made in general German terminology between 
Table 1 Characterization of air pollutants

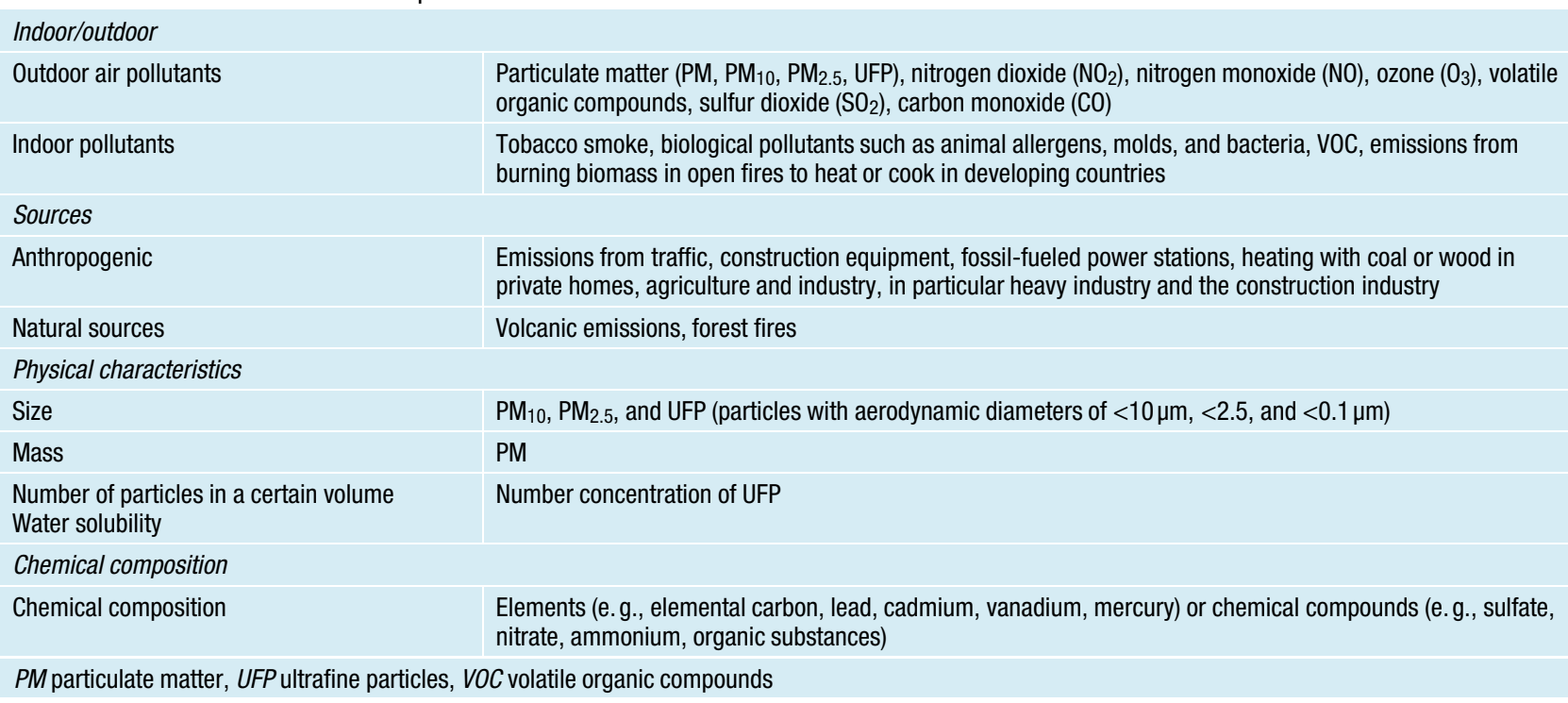

PM with an aerodynamic diameter of less than $10 \mu \mathrm{m}$ $\left(\mathrm{PM}_{10}\right)$ and particles with an aerodynamic diameter of less than $2.5 \mu \mathrm{m}\left(\mathrm{PM}_{2.5}\right)$, whereas in scientific terminology, the term "fine particulate matter" is reserved for $\mathrm{PM}_{2.5}$ particles. Nitrogen dioxide is considered an easy-to-measure indicator of the traffic-related overall mixture, even though direct negative effects on individuals with mild asthma have also been observed in experimental and epidemiological studies. The role played in health by nitrogen monoxide (NO) will not be discussed in more detail here, since NO is of less relevance in terms of health, is rapidly oxidized to $\mathrm{NO}_{2}$ following emission anyway, and $\mathrm{NO}_{2}$ is the air pollutant indicator more commonly used for trafficrelated emissions in epidemiological studies. As such, the focus of this article is on the two pollutants $\mathrm{PM}_{2.5}$ and $\mathrm{NO}_{2}$, taking into special consideration the situation in Germany and in German cities in particular. Nevertheless, it should be pointed out that PM is the air pollutant that poses the greatest and most diverse health risks in heavily trafficked cities; see, for example, the review articles on air pollution and airway diseases [1-3].

Air pollutants can be described by many characteristics (Table 1). In Germany, one on the whole finds the following sources of PM- $\left(\mathrm{PM}_{10}\right.$ and $\left.\mathrm{PM}_{2.5}\right)$ and $\mathrm{NO}_{2}$-related air pollution: local traffic emissions as well as air pollutants arising from industry or agriculture that are transported long distances. There are also emissions in rural regions from small-scale furnaces, used in particular to burn wood or wood pellets. In addition to exhaust fumes, traffic emissions also include the nonnegligible abrasion of brakes and tires, as well as the resuspension of settled dust. Traffic emissions, in particular those from diesel vehicles, contribute significantly to polluting the air with nitrogen oxides $\left(\mathrm{NO}_{\mathrm{x}}\right)$. Moreover, older diesel vehicles without particle filters represent a major source of PM pollution, in particular $\mathrm{PM}_{2.5}$ and $\mathrm{NO}_{\mathrm{x}}$.

The following article looks only at pollutants in outdoor air, although exposure to tobacco smoke as a result of active and passive smoking, i.e., the inhalation of tobacco smoke caused by third parties, has shown the clearest effects of all air pollutants in terms of the development of asthma and exacerbations of existing asthma [4-6].

When investigating the health effects of exposure to polluted air, a general distinction needs to be made between those effects that explain the onset of disease and those effects that cause exacerbations, increased drug use, or more rapid progression of existing disorders. Numerous studies have unanimously shown that $\mathrm{PM}\left(\mathrm{PM}_{10}, \mathrm{PM}_{2.5}\right)$ and $\mathrm{NO}_{2}$ exposure in asthmatics causes more exacerbations (more respiratory tract symptoms), poorer pulmonary function, and greater drug use in children as well as in adults [7-9]. Likewise, $\mathrm{PM}$ and $\mathrm{NO}_{2}$ exposure in patients with chronic obstructive pulmonary disease (COPD) results in more frequent exacerbations, poorer pulmonary function, and accelerated disease progression [10]. However, with regard to the potential for the primary prevention of allergic diseases by avoiding or reducing exposure to these air pollutants, these important results are irrelevant to affected patients.

This article discusses the potential to prevent allergies by avoiding or reducing high air pollution exposure to $\mathrm{PM}_{2.5}$ and $\mathrm{NO}_{2}$. Thus, the aim is to investigate the risks for primarily healthy individuals to develop an allergy as a function of air pollution exposure. First of all, however, an example highlighting the complexity of the study aim is presented below. 


\section{A comparison of allergy prevalences in East and} West Germany

Let us begin with a historical digression: 30 years ago, physicians as well as the public unanimously believed that air pollutants could cause asthma and allergic rhinitis. This belief was fueled by physicians and asthmatics who observed a link between the inhalation of polluted air and asthma symptoms. Prior to the fall of the Berlin wall, there were no systematic investigations on the prevalence of asthma and allergic rhinitis in East and West Germany. However, it was generally known that the air in East Germany was extremely polluted with harmful substances such as total suspended particles (particles of all sizes up to $35 \mu \mathrm{m}$ ) and sulfur dioxide. Therefore, it was assumed that the prevalence of asthma, allergic rhinitis, and also eczema must be much higher in the East German population compared with that in West Germany [11]. However, at the beginning of the 1990s, it was demonstrated-to worldwide surprise-that the prevalence of asthma and allergic rhinitis both in children [12] and in adults [13] in the general East German population was significantly lower compared with the West German population. Medical investigations into the prevalence of sensitization by means of skin prick testing or specific immunoglobulin $\mathrm{E}$ (IgE) measurements and bronchial hyperreactivity measurements supported these regional differences. This gave rise to speculation that the surprisingly high allergy prevalence in West Germany was merely a methodological artifact resulting from medical underdiagnosis or lower awareness of these disorders in East Germany. One must therefore assume that morbidity due to asthma and allergic rhinitis was in actual fact lower in East Germany. This was an unexpected result, which was initially not understood and sometimes incorrectly interpreted: as though air pollution exposure is not relevant to allergy development. This fallacy was further fostered by followup investigations. Following the fall of the Berlin wall, the breakdown of East German heavy industry, and a shift in energy sources from almost exclusively lignite to hard coal, oil, and gas, air quality in East Germany improved considerably within only a few years. Sulfur dioxide levels fell to around $10 \%$ of their baseline levels within 3 years, and PM and total suspended particle levels to approximately $50 \% . \quad \mathrm{NO}_{2}$ levels also fell, but not to such an extent [14, 15] (for more on this, see the website of the German Federal Environment Agency, Umweltbundesamt). However, parallel to this improvement in air hygiene conditions, asthma and allergic rhinitis rates increased in East German children [11, 16, 17]. Within only 7 years of the fall of the wall, a representative Germany-wide survey of over 1700 children and adolescents showed that the allergy prevalences between East and West Germany had become aligned and that there were no longer significant differences $[18,19]$. What can one learn from these study results? Asthma and allergic rhinitis are known to be complex diseases that can result from the interplay between genetic disposition, lifestyle, and environmental exposure. Although it was not possible for the gene pool and genetic predisposition in East Germany to change within only a few years of the fall of the wall, epigenetic effects due to modified living conditions and behaviors are conceivable. Improved air hygiene represents only one of many factors in the spectrum of extreme changes to all areas of life in East Germany following the fall of the Berlin wall. Epidemiological studies highlight the crucial role played by lifestyle factors following the fall of the wall and show that outdoor air pollutants are of secondary importance. One must also bear in mind here that the sources of air pollutants changed. Along with different sources, a reduction in particle size, and hence altered atmospheric conversion processes, there also came changes in the composition of pollutants [15]. Finally, it should be mentioned that a similar trend has been observed among East European neighbors, albeit less rapid. For example, studies comparing Finland (Karelia) and Sweden with Russia (East Karelia), Estonia, and Poland revealed a lower prevalence of asthma and allergic rhinitis in East European regions with higher exposure [20-23]. Here again, the causes were interpreted in terms of altered living conditions and behaviors. In this context, one refers to factors of "Western lifestyle" [24]. These include:

- Environmental factors: An increase in traffic-related pollutants; better insulation of residential buildings leads to a reduction in air exchange rates as well as possibly to indoor mold problems and greater exposure to chemicals emitted indoors

- Lifestyle factors: more convenience food and other consumption patterns, more foreign travel and resultant contact with foreign allergens, less physical activity, more stress, in particular shortly after the breakdown of the GDR as a result of high unemployment, anxiety about the future, more living space, and hence less "crowding"

- Other factors: fewer infectious diseases in early childhood, rarer infestation with worms and other parasites; generally less exposure to bacteria, fewer siblings, later contact with large numbers of children due to later attendance at child daycare centers

It is important to point out here that none of these Western lifestyle factors alone is able to explain the increase in allergies in East German children [11]. Evidently, the rise in allergies in transition societies can only be adequately explained by a combination of several or all of these factors, or hitherto unidentified factors. 
Air pollution exposure and allergies in epidemiological studies

Over the past 20 years, numerous epidemiological studies have investigated the effect of air pollutants on the onset of allergies. Whereas the effect of air pollutants on exacerbations, symptom worsening, and increased drug use is undisputed [9], the results on the long-term effects on allergies are apparently conflicting to this day (see the results of the following systematic reviews: $[7,8,25-30])$. Meanwhile, it has become difficult to get an overview of the large number of original publications and numerous reviews and evaluate their evidence. What is striking here is that these reviews reach different conclusions in terms of the evidence for a causal link between air pollutants and asthma, even though some were published in the same year. The reason for this is that the relevant studies in terms of methodology, results, and robustness of results are highly heterogeneous and the respective criteria for including a study in a review differ extensively. In addition to this, individual authors likely have a subjective preference for a stricter or more liberal understanding of "causality." The methodological differences between the studies are extremely important to understanding the different conclusions drawn by the review articles and are therefore presented below:

- Underlying design: cross-sectional studies, cohort studies, case crossover studies, registry studies, and use of routine statistical data

- Allergic diseases investigated and allergy risk markers: asthma, allergic rhinitis, allergic sensitization, dermatitis and how these are methodologically determined (self-reporting by subjects, medical examination, registry study data)

- Air pollutants included: $\mathrm{PM}_{10}, \mathrm{PM}_{2.5}$, black smoke, $\mathrm{NO}_{2}$, coarse particles $\left(\mathrm{PM}_{10-2.5}\right)$, ozone, $\mathrm{SO}_{2}$, trafficrelated air pollution (TRAP)

- Exposure estimate: individual exposure estimate using land-use regression (LUR) models or dispersion models, calculating the distance to the main source of air pollution emitters by means of geographic information systems (GIS) or self-reporting

- Main sources of air pollution levels: traffic, power stations, and heavy industry, etc.

- Continent and region

- Children and adults, recruiting mode, and number of study participants included

This heterogeneity between studies makes it difficult to reliably answer the question as to whether air pollutants (and if so, which pollutants) cause the onset of allergic diseases (and if so, which diseases). Crucial here is which studies are selected to answer this question and based on what rationale. In order to limit the heterogeneity between studies and focus on the qualitatively best analyses, those studies (and their systematic review) that met the following criteria have been selected for this article:

- Prospective study design beginning at birth (birth cohort studies)

- Reliable data on asthma, allergic rhinitis, and allergic sensitization through repeated and, where appropriate, medical examinations

- Individual estimate of exposure to $\mathrm{PM}_{10}, \mathrm{PM}_{2.5}$, and $\mathrm{NO}_{2}$ using LUR or dispersion models

- Neonates observed to adolescence

Birth cohort studies are superior to all other designs, since they take into account the perinatal period, which is a potentially relevant time window of exposure; lifelong exposure can be determined despite relocations; neonates and young children are considered particularly vulnerable to air pollutants [31]; and, finally, the time course of diseases and their remission can be best evaluated. For this reason, the relationships between air pollution exposure and selected allergic diseases are presented for the last systematic review of birth cohorts [29] in a first step and, in a second step, these are expanded on by the summaries of other systematic reviews and high-quality original publications that were published after this review.

Altogether, 15 studies, with results published up to January 2016, were identified in the relevant databases in the last systematic review on the subject of air pollutants and allergies in birth cohorts [29]. Of these, eight were located in Europe (Oslo, Norway; BAMSE, Sweden; GINIplus and LISAplus, Germany; PIAMA, the Netherlands; INMA, Spain; GASPII, Italy; MAAS; Great Britain), four in Canada (SAGE, CAPPS, CHILD, and BCBC), two in the US (CCAAPS and CCCEF), and one in Taiwan (TBCS). The cohort sample size varied between 178 (SAGE, Canada) and 37401 (BCBC, Canada). The majority of studies on asthma had a relatively long observation period of approximately 10 years. The prevalence of allergic diseases varied between cohorts: $4-10.9 \%$ for asthma, $5-28.9 \%$ for a main asthma symptom (wheezing), $2.6-11.5 \%$ for allergic rhinitis, $16-40.4 \%$ for allergic sensitization to aero- or food allergens, and $4.9-15.5 \%$ for eczema. These differences are mainly due to the selection of a high-risk population (CAPPS) and differences in the observation time and, thus, in the age of subjects. To this, one can add geographic and cultural factors, which affect the prevalence of allergies. Most subjects were exposed to air pollutants that fall below the WHO recommendations of $10 \mu \mathrm{g} / \mathrm{m}^{3}$ for $\mathrm{PM}_{2.5}$ and $40 \mu \mathrm{g} / \mathrm{m}^{3}$ for $\mathrm{NO}_{2}$. All studies were able to draw on individually determined exposure data, and most on LUR modeling results.

\section{Asthma}

The pooled estimate for $\mathrm{PM}_{2.5}$ and incident asthma for the seven birth cohorts was elevated, but not statistically significant (odds ratio [OR] 1.24; 95\% confidence 
Fig. 1 Asthma risk at a PM 2.5 increment of $2 \mu \mathrm{g} / \mathrm{m}^{3}$. $\mathrm{OR}$ odds ratio, $\mathrm{Cl}$ confidence interval. (Modified after [29])

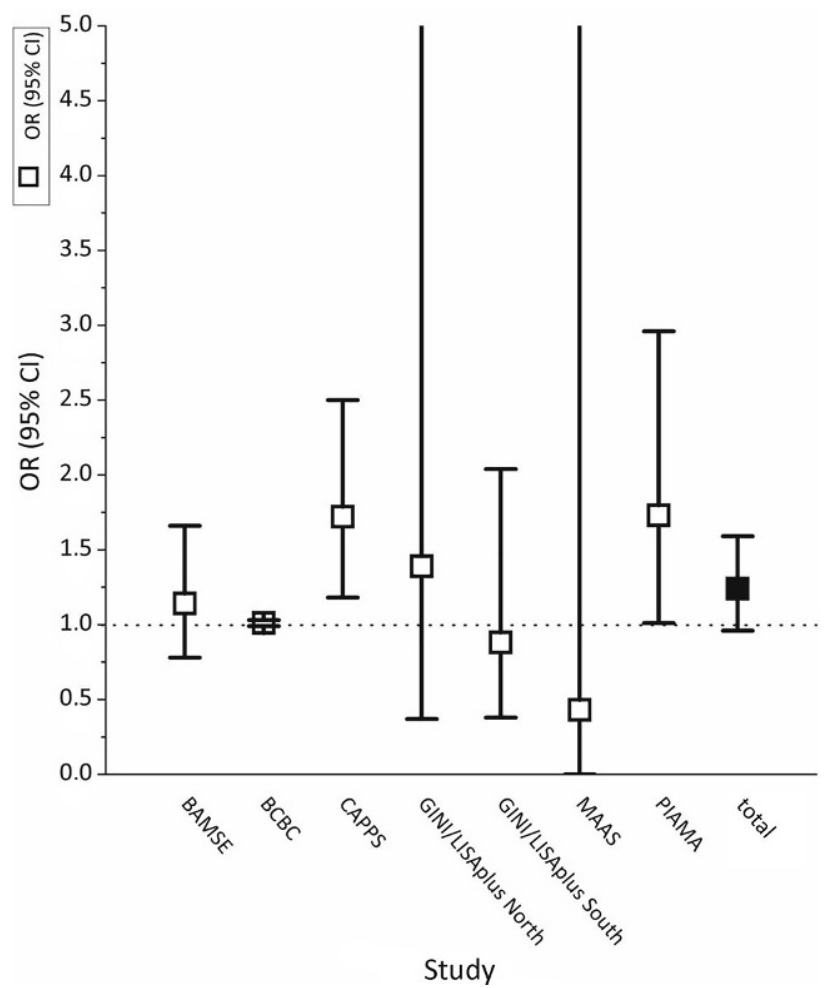

\begin{tabular}{|l|l|l|l|}
\hline Cohort & Location & OR (95\% CI) & Reference \\
\hline BAMSE & Sweden & $1.14(0.78-1.66)$ & Gehring et al. 2015 \\
\hline BCBC & Canada & $1.01(0.99-1.03)$ & Clark et al. 2010 \\
\hline CAPPS & Canada & $1.72(1.18-2.50)$ & Maclntyre et al. 2014 \\
\hline GINI/LISAplus North & Germany & $1.39(0.37-5.23)$ & Gehring et al. 2015 \\
\hline GINI/LISAplus South & Germany & $0.88(0.38-2.04)$ & Gehring et al. 2015 \\
\hline MAAS & Great Britain & $0.43(0.00-739.56)$ & Mölter et al. 2015 \\
\hline PIAMA & The Netherlands & $1.73(1.01-2.96)$ & Gehring et al. 2015 \\
\hline Total & & $\mathbf{1 . 2 4}(\mathbf{0 . 9 6 - 1 . 5 9 )}$ \\
\hline
\end{tabular}

interval [CI] 0.96-1.59) at a $\mathrm{PM}_{2.5}$ increment of $2 \mu \mathrm{g} / \mathrm{m}^{3}$ (Fig. 1). The effects were heterogeneous between the individual studies. The estimate of the effect of $\mathrm{NO}_{2}$ was based on 10 studies with appropriate data and was similarly high (OR 1.08; 95\% CI $0.96-1.20$ ) at an $\mathrm{NO}_{2}$ increment of $10 \mu \mathrm{g} / \mathrm{m}^{3}$ (Fig. 2). These results are similar to those of a meta-analysis of European cohort study data [32]. In that particular study, data from largely the same studies were analyzed, but with a shorter observation period. A third meta-analysis of birth cohort data on air pollution and asthma confirms these findings [26], assuming the corrections [33] are taken into account. The increased risks for asthma, as well as the heterogeneity between studies, can be explained by the large Dutch birth cohort, PIAMA, which showed statistically significantly higher risks for asthma and $\mathrm{PM}_{2.5}$ [34]. The causes of this heterogeneity of effects are not yet understood, since all European studies are extremely similar in terms of methodology. Possible causes of heterogeneity include the different sources of air pollution in the individual studies and the varying levels of urbanization between cohorts, given that some cohorts, such as the Dutch PIAMA study, also included rural regions. Thus, the results from the birth cohorts, which are considered the studies of highest quality, reveal increased but not statistically significant risks for asthma in children depending on $\mathrm{PM}_{2.5}$ and $\mathrm{NO}_{2}$ [34].

Whereas the systematic reviews of birth cohort studies were able to include a maximum of 10 studies in their analyses, another systematic review published recently was able to consider 41 studies, since cross-sectional studies were also included [30]. These meta-analyses reveal pooled effects of OR 1.03 (95\% CI 1.01-1.05) for a $\mathrm{PM}_{2.5}$ increment of $1 \mu \mathrm{g} / \mathrm{m}^{3}$ and of OR 1.05 (95\% CI 1.02-1.07) for an $\mathrm{NO}_{2}$ increment of $4 \mu \mathrm{g} / \mathrm{m}^{3}$. Although some of these studies are less methodologically sophisticated and there are differ- 
Fig. 2 Asthma risk at an $\mathrm{NO}_{2}$ increment of $10 \mu \mathrm{g} / \mathrm{m}^{3}$ (OR odds ratio, $\mathrm{Cl}$ confidence interval). (Modified after [29])

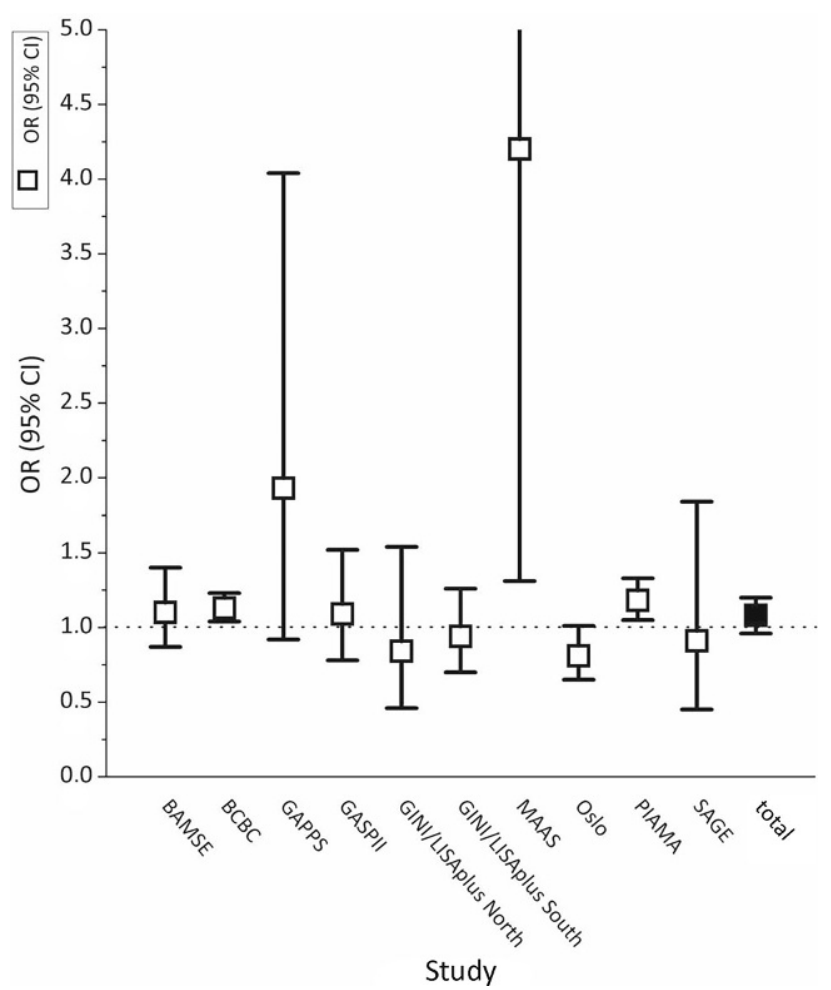

\begin{tabular}{|l|l|l|l|}
\hline Cohort & Location & OR (95\% Cl) & Reference \\
\hline BAMSE & Sweden & $1.10(0.87-1.41)$ & Gehring et al. 2015 \\
\hline BCBC & Canada & $1.13(1.04-1.23)$ & Clark et al. 2010 \\
\hline GAPPS & Canada & $1.93(0.92-4.03)$ & Maclntyre et al. 2014 \\
\hline GASPII & Italy & $1.09(0.78-1.52)$ & Ranzi et al. 2014 \\
\hline GINI/LISAplus North & Germany & $0.84(0.46-1.55)$ & Gehring et al. 2015 \\
\hline GINI/LISAplus South & Germany & $0.94(0.70-1.26)$ & Gehring et al. 2015 \\
\hline MAAS & Great Britain & $4.20(1.31-13.42)$ & Mölter et al. 2015 \\
\hline Oslo & Norway & $0.81(0.65-1.02)$ & Oftedal et al. 2009 \\
\hline PIAMA & The Netherlands & $1.18(1.05-1.33)$ & Gehring et al. 2015 \\
\hline SAGE & Canada & $0.91(0.45-1.83)$ & Maclntyre et al. 2014 \\
\hline Total & & $\mathbf{1 . 0 8 ( 0 . 9 6 - 1 . 2 0 )}$ & \\
\hline
\end{tabular}

ences between studies in terms of exposure assessment strategies, the collection of data on asthma, and the monitoring of confounding factors, the larger number of studies included significantly increases the power to detect air pollution effects. However, one should not forget that results of cross-sectional studies are not suited to determining the reasons for a causal relationship between air pollution and asthma.

Another systematic review conducted a few years earlier by Anderson et al. [25] also combined results from cross-sectional studies and prospective studies with similar results: the risk for asthma in childhood was statistically significantly increased depending on traffic-related air pollution.
The most comprehensive review of the topic traffic-related air pollution and asthma incidence reaches a more conservative conclusion, i. e., that there is insufficient evidence for a causal role [8]. This conclusion summarizes the state of knowledge from studies published up to 2010. Although numerous other studies have been published on this issue since then, no compellingly different assessment has emerged. This does nothing to change the pros [27, 35-41] and cons $[3,7,28,42]$ for the effect of air pollution on the development of childhood asthma in other reviews and statements over the past 20 years.

The role of air pollutants in the new onset of asthma in adulthood is even less well understood. The handful of relevant studies show inconsistent results. Three 
Fig. 3 Risk for allergic rhinitis at a $\mathrm{PM}_{2.5}$ increment of $2 \mu \mathrm{g} / \mathrm{m}^{3}$ (OR odds ratio, $\mathrm{Cl}$ confidence interval). (Modified after [29])

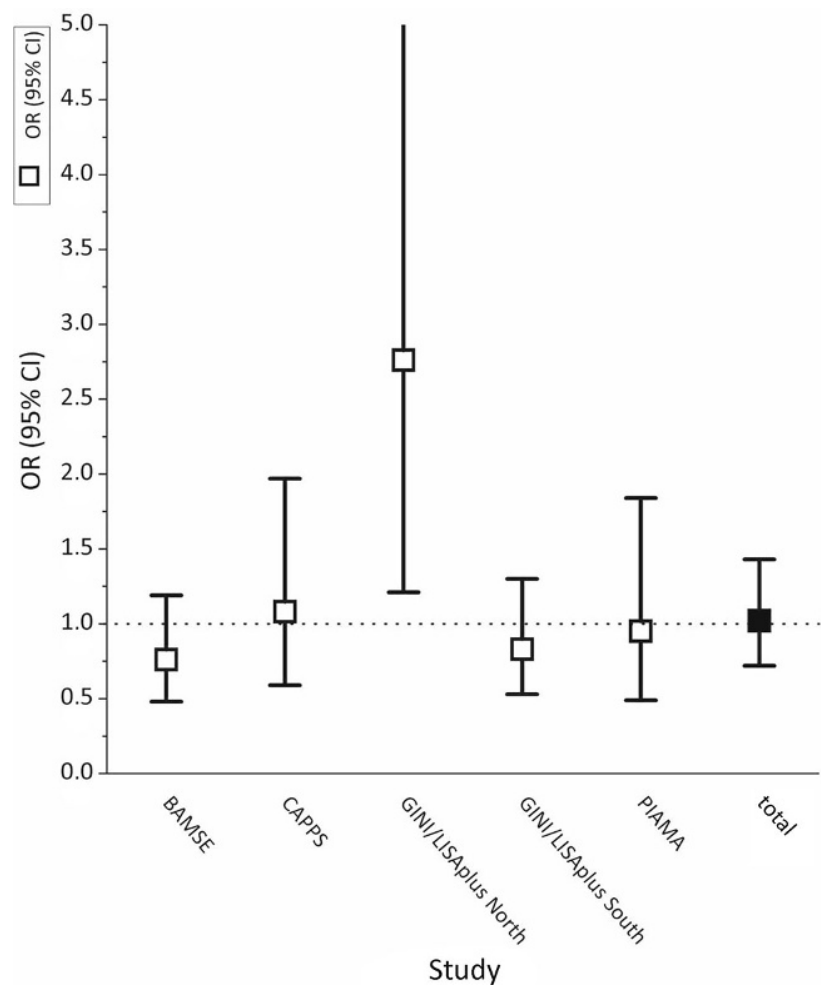

\begin{tabular}{|l|l|l|l|}
\hline Cohort & Location & OR (95\% Cl) & Reference \\
\hline BAMSE & Sweden & $0.76(0.48-1.19)$ & Gehring et al. 2015 \\
\hline CAPPS & Canada & $1.08(0.59-1.96)$ & Fuertes et al. 2013 \\
\hline GINI/LISAplus North & Germany & $2.76(1.21-6.33)$ & Gehring et al. 2015 \\
\hline GINI/LISAplus South & Germany & $0.83(0.53-1.31)$ & Gehring et al. 2015 \\
\hline PIAMA & The Netherlands & $0.95(0.49-1.84)$ & Gehring et al. 2015 \\
\hline Total & & $\mathbf{1 . 0 2 ( 0 . 7 2 - 1 . 4 3 )}$ & \\
\hline
\end{tabular}

studies report statistically significantly higher risks for asthma in increased $\mathrm{NO}_{2}$ exposure [43-45], as well as in a subpopulation of atopic individuals [46]. Other studies, some of which evaluate several cohorts together [47], reveal increased risks, which, however, are not statistically significant [47-50]. The handful of studies that have investigated the effects of $\mathrm{PM}_{2.5}$ on the new onset of asthma in adulthood found nonstatistically significantly increased risks $[47,49]$.

\section{Allergic rhinitis}

A meta-analysis of birth cohort data revealed no increased risk for allergic rhinitis either due to $\mathrm{PM}_{2.5}$ exposure (OR 1.02; 95\% CI 0.72-1.43) at a $\mathrm{PM}_{2.5}$ increment of $2 \mu \mathrm{g} / \mathrm{m}^{3}$ (based on five studies; Fig. 3) or $\mathrm{NO}_{2}$ exposure (OR 1.01; 95\% CI 0.85-1.19) at an $\mathrm{NO}_{2}$ increment of $10 \mu \mathrm{g} / \mathrm{m}^{3}$ (based this time on six studies; Fig. 4). Another meta-analysis that used largely the same cohort data also found no evidence that $\mathrm{PM}_{2.5}$ and $\mathrm{NO}_{2}$ exposure increases the risk for allergic rhinitis [51]. A number of recently published results from Chinese cross-sectional studies report positive links between $\mathrm{PM}_{2.5}$ and $\mathrm{NO}_{2}$ and allergic rhinitis in children [52-54]. It is not possible to conclusively assess to what extent the methodological weaknesses of a cross-sectional study, regional and cultural lifestyle factors, or, lastly, the significantly higher exposure levels in China are decisive for the differing results compared with the European and North American studies.

Long-term exposure to $\mathrm{PM}_{2.5}$ and $\mathrm{NO}_{2}$ was not associated with an increased incidence of allergic rhinitis in adults in two large European cohorts [55].

\section{Allergic sensitization}

Meta-analyses of birth cohort results revealed no statistically significant links between air pollution and allergic sensitization [56]. A weak, statistically non-significant association was reported for $\mathrm{PM}_{2.5}$ (OR 1.05; 95\%CI $1.00-1.11)$ per $2-\mu \mathrm{g} / \mathrm{m}^{3}$ increment and specific sensitization to aeroallergens, but not for $\mathrm{NO}_{2}$ (OR 1.02; 95\%CI $0.92-1.13$ ) per $10-\mu g / \mathrm{m}^{3}$ increment [29]. These associations are based on six and eight stud- 
Fig. 4 Risk for allergic rhinitis at an $\mathrm{NO}_{2}$ increment of $10 \mu \mathrm{g} / \mathrm{m}^{3}$ (OR odds ratio, $\mathrm{Cl}$ confidence interval). (Modified after [29])

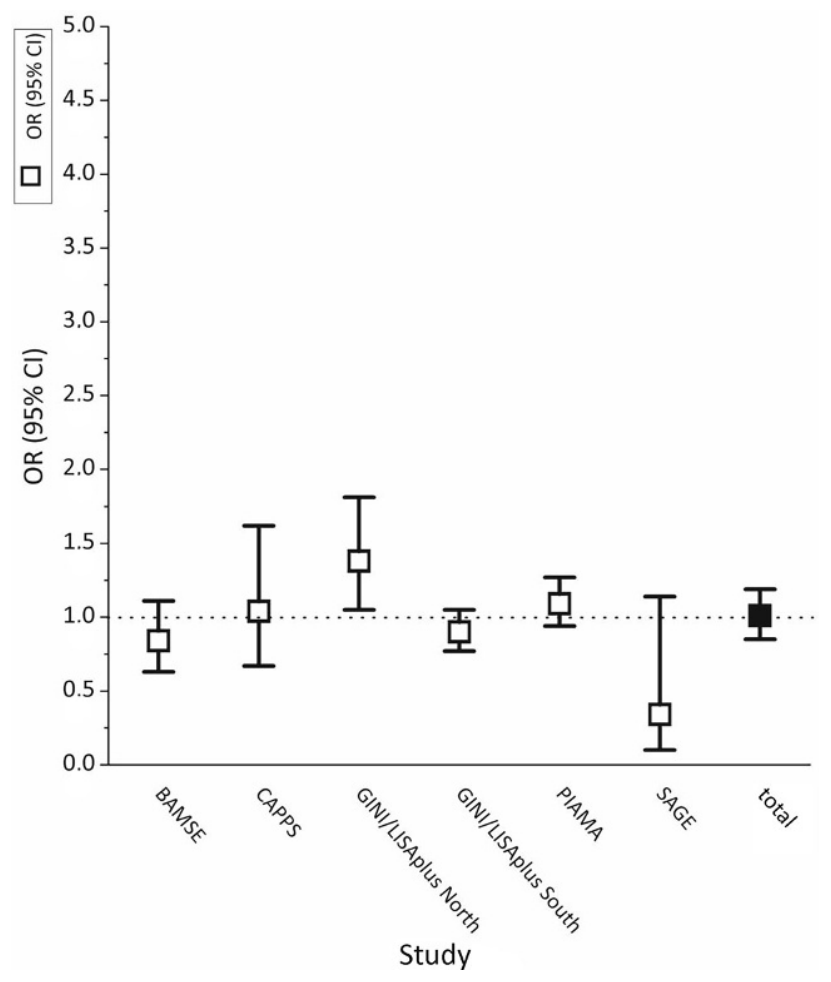

\begin{tabular}{|l|l|l|l|}
\hline Cohort & Location & OR (95\% CI) & Reference \\
\hline BAMSE & Sweden & $0.84(0.63-1.11)$ & Gehring et al. 2015 \\
\hline CAPPS & Canada & $1.04(0.67-1.63)$ & Fuertes et al. 2013 \\
\hline GINI/LISAplus North & Germany & $1.38(1.05-1.81)$ & Gehring et al. 2015 \\
\hline GINI/LISAplus South & Germany & $0.90(0.77-1.05)$ & Gehring et al. 2015 \\
\hline PIAMA & The Netherlands & $1.09(0.94-1.27)$ & Gehring et al. 2015 \\
\hline SAGE & Canada & $0.34(0.10-1.12)$ & Fuertes et al. 2013 \\
\hline Total & & $\mathbf{1 . 0 1 ( 0 . 8 5 - 1 . 1 9 )}$ \\
\hline
\end{tabular}

ies, respectively. Only one small Australian study on adults found statistically positive links between $\mathrm{NO}_{2}$ and allergic sensitization [57]. Therefore, the extent to which the lack of associations in childhood on the basis of virtually ideal study design with a large sample size should be interpreted more cautiously than a zero result remains questionable.

\section{Eczema}

Only a handful of studies have analyzed the links between air pollution exposure and the onset of eczema $[11,58-63]$. If anything, these studies generally describe skin symptoms-at different ages (6 months, 6 years, 8-11 years) - that manifest depending on different air pollutants $\left(\mathrm{PM}_{2.5}, \mathrm{NO}_{2}, \mathrm{SO}_{2}\right.$, and $\left.\mathrm{PM}_{10}\right)$ and which point to dermatitis. A recently published review on the role of air pollutants in dermatitis concluded that the results are controversial and that no conclusive evaluation could be made due to the scant number of studies and their methodological pitfalls
[64]. This evaluation refers to the role of air pollution in existing eczema as well as to air pollution's causation of eczema. The only meta-analysis on PM and skin disease presents results from 13 studies on $\mathrm{PM}_{2.5}$ exposure and atopic dermatitis in children and adults [65]. The joint effect estimate was not statistically significantly increased (OR 1.04; 95\% CI 0.96-1.12) for a $\mathrm{PM}_{2.5}$ increment of $10 \mu \mathrm{g} / \mathrm{m}^{3}$. The joint effect estimate for $\mathrm{PM}_{10}$ was below 1.00. Restricting the studies to only those including children did not alter the effect estimates significantly.

\section{Possible mechanisms}

While it is largely not possible to identify statistically significant links between the selected air pollutants $\left(\mathrm{PM}_{2.5}\right.$ and $\left.\mathrm{NO}_{2}\right)$ and asthma, allergic rhinitis, eczema, and allergic sensitization, the results of laboratory studies and human exposure support the hypothesis of a possible causal link between air pollution and allergies [3, 7, 8, 66-68]. The evidence yielded by these 
laboratory studies on the adverse effects of particles, especially PM and diesel particles, is particularly well demonstrated, while the role of $\mathrm{NO}_{2}$ is less clear, possibly due to less specialized studies on $\mathrm{NO}_{2}$. The following mechanisms are discussed as potentially underlying particle effects: epithelial stress, a particle-induced $\mathrm{Th} 2$ response, and an increased Th17 response [66]. In contrast, $\mathrm{NO}_{2}$ effects are discussed in association with neutrophilic bronchial infiltration, the production of proinflammatory cytokines, and adjuvant effects in allergen exposure [67]. What is particularly interesting here is the apparent inconsistency between immunological effects in the laboratory studies and the evidence that is largely lacking in the epidemiological observational studies for air pollution effects on allergic sensitization.

\section{Conclusion}

Despite conducting an extensive literature search, presenting the most recent results, and focusing on the qualitatively high birth cohort studies most relevant to the question in hand, this summary of epidemiological results does little to support the concept of a causal relationship between the two air pollutants in question, $\mathrm{PM}_{2.5}$ and $\mathrm{NO}_{2}$, and asthma. Although in vitro studies, animal models, and human exposure demonstrate plausible potential mechanisms between particle exposure and allergic biomarkers by affecting the innate and adaptive immune system, epidemiological studies overwhelmingly show no effects on allergic sensitization and the onset of hay fever and eczema.

Asthma and other IgE-mediated allergic diseases belong to the complex diseases of multifactorial etiology. Besides environmental effects, this also includes exposure that depends on lifestyle and behavior and is determined by genetic and epigenetic make-up [69]. As such, it is not surprising that it is impossible to filter out the effects of a single risk factor from numerous risk factors for allergies in the context of epidemiological observational studies.

If the evidence for a causal role of these air pollutants in the onset of allergies is not clearly demonstrated, one must logically conclude that the primary prevention of allergies due to the air pollutants considered here is likely to be impossible. However, there is strong and undisputed evidence that air pollutants can trigger exacerbations of allergic diseases [9]. This alone justifies ensuring that the existing threshold values for air pollutants are adhered to, in order to protect particularly allergy sufferers from health impairments. To this, one can add the negative effect on life expectancy, cardiovascular diseases, lung cancer (as recently proven), and increased infectious diseases in early childhood, to mention but a few examples. As such, air pollutants are clearly detrimental to the health and must be kept to a minimum.
Conflict of interest J. Heinrich declares that he has no competing interests.

Open Access This article is distributed under the terms of the Creative Commons Attribution 4.0 International License (http://creativecommons.org/licenses/by/4.0/), which permits unrestricted use, distribution, and reproduction in any medium, provided you give appropriate credit to the original author(s) and the source, provide a link to the Creative Commons license, and indicate if changes were made.

\section{References}

1. Perez L, Rapp R, Künzli N. The year of the lung: outdoor air pollution and lung health. Swiss Med Wkly. 2010;140:w13129.

2. Thurston GD, Kipen H, Annesi-Maesano I, Balmes J, Brook RD, Cromar K, et al. A jointERS/ATS policy statement: what constitutes an adverse health effect of air pollution? An analytical framework. Eur Respir J.2017;49:1600419.

3. Krzyzanowski M, Kuna-Dibbert B, Schneider J, editors. WHO Regional office for Europe. Health effects of transport-related air pollution. Copenhagen: World Health Organization Regional Office for Europe; 2005.

4. Dick S, Doust E, Cowie H, Ayres JG, Turner S. Associations between environmental exposures and asthma control and exacerbations in young children: a systematic review. BMJ Open. 2014;4:e3827.

5. Neuman A, Hohmann C, Orsini N, Pershagen G, Eller E, Kjaer HF, et al. Maternal smoking in pregnancy and asthma in preschool children: a pooled analysis of eight birth cohorts. Am J Respir Crit Care Med. 2012;186:1037-43.

6. Thacher JD, Gehring U, Gruzieva O, Strandl M, Pershagen $\mathrm{G}$, Bauer CP, et al. Maternal smoking during pregnancy and early childhood and development of asthma and Rhinoconjunctivitis-a meDALL project. Environ Health Perspect. 2018;126:47005.

7. Guarnieri M, Balmes JR. Outdoor air pollution and asthma. Lancet. 2014;383:1581-92.

8. HEI Panel on the Health Effects of Traffic-Related Air Pollution. Traffic-related air pollution: a critical review of the literature on emission, exposure, and health effects. HEI special report 17. Boston: Health Effects Institute; 2010.

9. Orellano P, Quaranta N, Reynoso J, Balbi B, Vasquez J. Effect of outdoor air pollution on asthma exacerbations in children and adults: systematic reviewand multilevelmetaanalysis. PLoSONE. 2017;12:e174050.

10. Heinrich J, Schikowski T. COPD patients as vulnerable subpopulation for exposure to ambient air pollution. Curr Environ Health Rep. 2018;5:70-6.

11. Krämer U, Schmitz R, Ring J, Behrendt H. What can reunification of East and West Germany tell us about the cause of the allergy epidemic? Clin Exp Allergy. 2015;45:94-107.

12. von Mutius E, Fritzsch C, Weiland SK, Röll G, Magnussen H. Prevalence of asthma and allergic disorders among children in united Germany: a descriptive comparison. BMJ. 1992;305:1395-9.

13. Nowak D, Heinrich J, Jörres R, Wassmer G, Berger J, Beck E, et al. Prevalence of respiratory symptoms, bronchial hyperresponsiveness and atopy among adults: west and east Germany. Eur Respir J. 1996;9:2541-52.

14. Ebelt S, Brauer M, Cyrys J, Tuch T, Kreyling WG, Wichmann HE, et al. Air quality in postunification Erfurt, East Germany: associating changes in pollutant concentrations with changes in emissions. Environ Health Perspect. 2001;109:325-33. 
15. Kreyling W, Tuch T, Peters A, Pitz M, Heinrich J, Stölzel M, et al. Diverging long-term trends in ambient urban particle mass and number concentrations associated with emission changes caused by the German unification. Atmos Environ. 2003;37:3841-8.

16. Heinrich J, Hoelscher B, Frye C, Meyer I, Wjst M, Wichmann HE. Trends in prevalence of atopic diseases and allergic sensitization in children in Eastern Germany. Eur Respir J. 2002;19:1040-6.

17. von Mutius E, Weiland SK, Fritzsch C, Duhme H, Keil $\mathrm{U}$. Increasing prevalence of hay fever and atopy among children in Leipzig, East Germany. Lancet. 1998;351:862-6.

18. Schlaud M, Atzpodien K, Thierfelder W. Allergic diseases. Resultsfrom theGermanHealthInterviewandExamination Survey for Children and Adolescents (KiGGS). BundesgesundheitsblattGesundheitsforschung Gesundheitsschutz. 2007;50:701-10.

19. Schmitz R, Atzpodien K, Schlaud M. Prevalence and riskfactors of atopic diseases in German children and adolescents. Pediatr Allergy Immunol. 2012;23:716-23.

20. AnnusT, Björkstén B, MaiXM, Nilsson L, RiikjärvMA, Sandin A, et al. Wheezing in relation to atopy and environmental factors in Estonian and Swedish schoolchildren. Clin Exp Allergy. 2001;31:1846-53.

21. Bråbäck L, Breborowicz A, Dreborg S, Knutsson A, PieklikH, Björkstén B. Atopic sensitization and respiratory symptoms amongPolish and Swedish schoolchildren. Clin ExpAllergy. 1994;24:826-35.

22. Riikjärv MA, Annus T, Bråbäck L, Rahu K, Björkstén B. Similar prevalence of respiratory symptoms and atopy in Estonian schoolchildren with changing lifestyle over 4 yrs. Eur Respir J. 2000;16:86-90.

23. Vartiainen E, Petäys T, Haahtela T, Jousilahti P, Pekkanen J. Allergic diseases, skin prick test responses, and IgE levels in North Karelia, Finland, and the Republic of Karelia, Russia. JAllergy Clin Immunol. 2002;109:643-8.

24. Wichmann HE. Possible explanation for the different trends of asthma and allergy in East and West Germany. Clin Exp Allergy. 1996;26:621-3.

25. Anderson HR, Favarato G, Atkinson RW. Long-term exposure to air pollution and the incidence of asthma: meta-analysis of cohort studies. Air Qual Atmos Health. 2013;6:47-56.

26. Bowatte G, Lodge C, LoweAJ, Erbas B, PerretJ,Abramson MJ, et al. The influence of childhood traffic-related air pollution exposure on asthma, allergy and sensitization: a systematic review and a meta-analysis of birth cohort studies. Allergy. 2015;70:245-56.

27. Gasana J, Dillikar D, Mendy A, Forno E, Ramos Vieira E. Motor vehicle air pollution and asthma in children: a metaanalysis. Environ Res. 2012;117:36-45.

28. Gowers AM, Cullinan P, Ayres JG, Anderson HR, Strachan DP, Holgate ST, et al. Does outdoor air pollution induce new cases of asthma? Biological plausibility and evidence; a review. Respirology. 2012;17:887-98.

29. Heinrich J, Guo F, Fuertes E. Traffic-related air pollution exposure and asthma, hayfever, and allergic sensitisation in birth cohorts: a systematic review and meta-analysis. Geoinfor Geostat Overv. 2016;4:4.

30. Khreis H, Kelly C, Tate J, ParslowR, Lucas K, Nieuwenhuijsen M. Exposure to traffic-related air pollution and risk of development of childhood asthma: a systematic review and meta-analysis. Environ Int. 2017;100:1-31.

31 . Heinrich J, Slama R. Fine particles, a major threat to children. Int JHyg Environ Health. 2007;210:617-22.

32. Mölter A, Simpson A, Berdel D, Brunekreef B, Custovic A, Cyrys J, et al. A multicentre study of air pollution exposure and childhood asthma prevalence: the ESCAPE project. Eur Respir J.2015;45:610-24.

33. Fuertes E, Heinrich J. The influence of childhood trafficrelated air pollution exposure on asthma, allergy and sensitization. Allergy. 2015;70:1350-1.

34. Gehring U, Beelen R, Eeftens M, Hoek G, de Hoogh K, de Jongste JC, et al. Particulate matter composition and respiratory health: the PIAMA Birth Cohort study. Epidemiology. 2015;26:300-9.

35. Beasley R, Semprini A, Mitchell EA. Risk factors for asthma: is prevention possible? Lancet. 2015;386:1075-85.

36. Bråbäck L, Forsberg B. Does traffic exhaust contribute to the development of asthma and allergic sensitization in children: findings from recent cohort studies. Environ Health. 2009;8:17.

37. Keet CA, Keller JP, Peng RD. Long-term coarse particulate matter exposure is associated with asthma among children in medicaid. Am J Respir Crit Care Med. 2018;197:737-46.

38. Pollock J, Shi L, Gimbel RW. Outdoor environment and pediatric asthma: an update on the evidence from north America. Can Respir J.2017;2017:8921917.

39. Rice MB, Rifas-Shiman SL, Litonjua AA, Gillman MW, Liebman N, Kloog I, et al. Lifetime air pollution exposure and asthma in a pediatric birth cohort. J Allergy Clin Immunol. 2018;141:1932-1934.e7.

40. Salam MT, Islam T, GillilandFD. Recent evidence for adverse effects of residential proximity to traffic sources on asthma. Curr Opin Pulm Med. 2008;14:3-8.

41. LavigneÉ, Bélair MA, Rodriguez Duque D, Do MT, Stieb DM, Hystad P, et al. Effect modification of perinatal exposure to air pollution and childhood asthma incidence. Eur Respir J. 2018;1701884. https://doi.org/10.1183/13993003.018842017. [Epub ahead of print]

42. Heinrich J, Wichmann HE. Traffic related pollutants in Europe and their effect on allergic disease. Curr Opin Allergy Clin Immunol. 2004;4:341-8.

43. Bowatte G, Erbas B, Lodge CJ, Knibbs LD, Gurrin LC, Marks GB, et al. Traffic-related air pollution exposure over a 5-year period is associated with increased risk of asthma and poor lung function in middle age. Eur Respir J. 2017;50:1602357.

44. Jacquemin B, Sunyer J, Forsberg B, Aguilera I, Briggs D, García-Esteban R, et al. Home outdoor NO2 and new onset of self-reported asthma in adults. Epidemiology. 2009;20:119-26.

45. Modig L, Torén K, Janson C, Jarvholm B, Forsberg B. Vehicle exhaust outside the home and onset of asthma among adults. Eur Respir J.2009;33:1261-7.

46. Modig L, Järvholm B, Rönnmark E, Nyström L, Lundbäck B, Andersson C, et al. Vehicle exhaust exposure in an incident case-control study of adult asthma. Eur Respir J. 2006;28:75-81.

47. Jacquemin B, Siroux V, Sanchez M, Carsin AE, Schikowski T, Adam M, et al. Ambient air pollution and adult asthma incidence in six European cohorts (ESCAPE). Environ Health Perspect. 2015;123:613-21.

48. Bowatte G, Lodge CJ, Knibbs LD, Erbas B, Perret JL, Jalaludin B, et al. Traffic related air pollution and development and persistence of asthma and low lung function. Environ Int. 2018;113:170-6.

49. Young HN, Larson TL, Cox ED, Moreno MA, Thorpe JM, MacKinnon NJ. The active patient role and asthma outcomes in an underserved rural community. J Rural Health. 2014;30:121-7.

50. Havet A, Zerimech F, Sanchez M, Siroux V, Le Moual N, Brunekreef B, et al. Outdoor air pollution, exhaled 8-isoprostane and current asthma in adults: the EGEA study. Eur Respir J.2018;51:1702036. 
51. Gehring U, Wijga AH, Hoek G, Bellander T, Berdel D, Brüske I, et al. Exposure to air pollution and development of asthma and rhinoconjunctivitis throughout childhood and adolescence: apopulation-based birth cohortstudy. Lancet Respir Med. 2015;3:933-42.

52. Chen F, Lin Z, Chen R, Norback D, Liu C, Kan H, et al. The effects of $\mathrm{PM}_{2.5}$ on asthmatic and allergic diseases or symptoms in preschool children of six Chinese cities, based on China, Children, Homes and Health $(\mathrm{CCHH})$ project. Environ Pollut. 2018;232:329-37.

53. Deng Q, Lu C, Yu Y, Li Y, Sundell J, Norbäck D. Early life exposure to traffic-related air pollution and allergic rhinitis in preschool children. Respir Med. 2016;121:67-73.

54. Teng B, Zhang X, Yi C, Zhang Y, Ye S, Wang Y, et al. The Association between Ambient Air Pollution and Allergic Rhinitis: Further Epidemiological Evidence from Changchun, Northeastern China. Int J Environ Res Public Health. 2017;14:E226.

55. Burte E, Leynaert B, Bono R, Brunekreef B, Bousquet J, Carsin AE, et al. Association between air pollution and rhinitis incidence in two European cohorts. Environ Int. 2018;115:257-66.

56. Gruzieva O, Gehring U, Aalberse R, Agius R, Beelen R, Behrendt $\mathrm{H}$, et al. Meta-analysis of air pollution exposure association with allergic sensitization in European birth cohorts. JAllergy Clin Immunol. 2014;133:767-776.e7.

57. Bowatte G, Lodge CJ, Knibbs LD, Lowe AJ, Erbas B, Dennekamp M, et al. Traffic-related air pollution exposure is associated with allergic sensitization, asthma, and poor lung function in middle age. J Allergy Clin Immunol. 2017;139:122-129.e1.

58. Gehring U, Wijga AH, Brauer M, Fischer P, de Jongste JC, Kerkhof M, et al. Traffic-related air pollution and the development of asthma and allergies during the first 8 years oflife. Am J Respir Crit Care Med. 2010;181:596-603.
59. Huang CC, Wen HJ, Chen PC, Chiang TL, Lin SJ, Guo YL. Prenatal air pollutant exposure and occurrence of atopic dermatitis. BrJDermatol. 2015;173:981-8.

60. Lee YL, Su HJ, Sheu HM, Yu HS, Guo YL. Traffic-related air pollution, climate, and prevalence of eczema in Taiwanese school children. J Invest Dermatol. 2008;128:2412-20.

61. Pénard-Morand C, Raherison C, Charpin D, Kopferschmitt C, Lavaud F, Caillaud D, et al. Long-term exposure to closeproximity air pollution and asthma and allergies in urban children. Eur Respir J. 2010;36:33-40.

62. Liu W, Cai J, Huang C, Hu Y, Fu Q, Zou Z, et al. Associations of gestational and early life exposures to ambient air pollution with childhood atopic eczema in Shanghai, China. Sci Total Environ. 2016;572:34-42.

63. Lu C, Deng L, Ou C, Yuan H, Chen X, Deng Q. Preconceptional and perinatal exposure to traffic-related air pollution and eczema in preschool children. J Dermatol Sci. 2017;85:85-95.

64. Ahn K. The role of air pollutants in atopic dermatitis. JAllergy Clin Immunol. 2014;134:993-9. discussion 1000.

65. Ngoc LTN, Park D, Lee Y, Lee YC. Systematic review and meta-analysis of human skin diseases due to particulate matter. Int JEnviron Res Public Health. 2017;14:E1458.

66. Brandt EB, Myers JM, Ryan PH, Hershey GK. Air pollution and allergic diseases. Curr Opin Pediatr. 2015;27:724-35.

67. Kim KH, Jahan SA, Kabir E. A review on human health perspective of air pollution with respect to allergies and asthma. Environ Int. 2013;59:41-52.

68. Schaumann F, Frömke C, Dijkstra D, Alessandrini F, Windt $\mathrm{H}$, Karg E, et al. Effects of ultrafine particles on the allergic inflammation in the lung of asthmatics: results of a doubleblinded randomized cross-over clinical pilot study. Part Fibre Toxicol. 2014;11:39.

69. Eder W, Ege MJ, von Mutius E. The asthma epidemic. NEngl JMed. 2006;355:2226-35. 